\title{
Food Portions and Marketing: Editorial
}

\author{
Søren Askegaard, University of Southern Denmark, Odense \\ Chris Dubelaar, Deakin University \\ Natalina Zlatevska, University of Technology Sydney \\ Stephen S Holden, Macquarie Graduate School of Management
}

Submission: July 2016

Revision: September 2016

Accepted: September 2016

Søren Askegaard (corresponding author), Dept. of Marketing \& Management, University of

Southern Denmark, Campusvej 55, 5230 Odense M, Denmark, Telephone: +45 655032 55, aske@sam.sdu.dk

Chris Dubelaar, Deakin Business School, Deakin University, 1 Gheringhap Street, Geelong 3220 Australia c.dubelaar@,deakin.edu.au

Natalina Zlatevska, Marketing Discipline Group, University of Technology Sydney, Ultimo, NSW 2007 Natalina.Zlatevska@uts.edu.au

Stephen S Holden, Macquarie Graduate School of Management, 99 Talavera Road, North Ryde, NSW, 2113, stephen.holden@mgsm.edu.au

Key words: food marketing, portion size, obesity 


\title{
Food Portions and Marketing: Editorial
}

\begin{abstract}
This special issue explores the role of portion sizes in food consumption, and the ways in which portion sizes may be used to regulate or reduce consumption. The papers address three sub-themes: consumer responses to portion sizes, the effect of partitioning a portion, and portion size cognitions and perceptions. This collection of papers is offered to assist both researchers and practitioners better understand how portion size affects food consumption. More importantly, the papers are offered so as to encourage and enable marketers to contribute positively in the fight against the growing prevalence of obesity.
\end{abstract}




\section{Introduction}

Obesity has been recognised as one of the leading causes of preventable illnesses in our modern time (WHO 2012, 2016). A report from the McKinsey Global Institute estimates the global economic impact of obesity is $\$ 2$ trillion, only slightly less than that of smoking or armed violence, war and terrorism (Dobbs et al. 2014). However, the problem of obesity is not only large, but very complex, even a wicked problem (Rittel and Webber 1973). At a simple level, obesity is considered to arise from a sustained energy imbalance, that energy intake (food eaten) is greater than the energy output. Despite the simple model however, the obesity problem is complicated because it is based on human behavior, much of that automatic in nature, and in turn is a function of many influences. Energy intake and energy output are difficult for humans to regulate. Obesity is therefore, the result of a complex interaction between body composition and food intake regulation (Flatt 1997). Alternatively, "as soon as weight is lost, there is a powerful biological drive to regain it" but no corresponding drive to lose it (by eating less or moving more) when we gain weight (PiSunyer 2003, p.859). This apparently innate bias in behavior is compounded by the fact that we live in a world in which food is abundant, nourishing (energy-dense) and cheap, and in an environment which simultaneously discourages and encourages weight gain. Therefore, despite public health efforts and social disapproval which tend to discourage obesity, natural parental desires for thriving children, junk-food marketing and social efforts decrying marketing's portrayal of overly-idealised physical types all tend to support, or at least do little to block the growth of obesity.

Food consumption and notably the provision of large portions of energy dense foods at cheap prices has become a focal point in meeting the challenge of obesity. Regulation of food marketing is increasingly targeted as one of the main approaches to limiting or reversing over-consumption (Seiders and Petty 2004). Of the various elements of the food marketing 
mix, the collected evidence offers strong support for the supposition that portion size is a major contributor to the growth of over-consumption, and also, that portion size may have the potential to contribute importantly in addressing the problem of obesity. A meta-analysis of the many studies that have examined the effect of portion size on consumption has revealed that portion size has an elasticity of .35 . That is, a doubling of portion size leads to a $35 \%$ increase in consumption (Zlatevska, Dubelaar, Holden 2014). However, the meta analysis also suggested that the relationship was curvilinear such that the portion size effect appears to be greater when applied to smaller portion sizes and increasingly reduced with everincreasing portion sizes. More recent research provides solid empirical evidence for the approximate elasticity of the portion size effect and its curvilinear nature (Rolls, Kling, Roe, 2016). While the bulk of existing research deals with the effect of portion size on consumption, there is also accumulating research suggesting that portion size has a strong effect on weight with a recent meta-analysis showing that that a $30 \%$ reduction in portion size can lead to a loss of about 2kgs ( 4lbs) per month (Zlatevska \& Holden, 2016).

Encouragingly then, just as the strong effect of portion size on consumption has contributed to the problem, this same effect has the potential to be harnessed in the battle against obesity. A report from the McKinsey Global Institute suggests that controlling portion size may be one of the single, most effective ways of reducing obesity and should be used in conjunction with multiple approaches to tackle obesity (Dobbs et al. 2014).

This special issue explores the role of portion sizes in food consumption, and the ways in which it may be used to regulate or reduce consumption. The collected papers are intended to assist both researchers and practitioners in building a better understanding of how portion size affects food consumption, and ultimately, to allow marketers to make a positive contribution to fighting the current growth in prevalence of obesity.

There are three general themes that run through the papers in this special issue: 
1. Consumer responses to portion sizes

2. The effect of partitioning a portion

3. Portion size cognitions and perceptions

\section{Responses to Portion Sizes}

The first theme addresses broader societal responses to portion sizes beyond the effect of portion size on consumption. The papers in this section examine how consumers and the public at large relate to and respond to portion sizes.

The first article Mystification and Obfuscation in Marketing of U.K. Food Products by Szmigin and Gee, takes a critical marketing perspective to portion size research, and aims at redirecting the focus in terms of food choice from an individual responsibility framework to that of a socially constructed marketing environment. Based on a systematically sampled selection of products from the categories of breakfast cereals, chocolate bars and yogurts, the authors analyze various elements of the nutritional and promotional information provided through the packaging, in particular in relation to portion size. They demonstrate how, in spite of the "objective" information available, the communicative result is a process of mystification and obfuscation about healthiness, portion size, and caloric content.

Consequently, the marketing of these products may lead to what is usually termed passive overconsumption. The paper concludes with an appeal for more transparent and comparable criteria for operating with portion size, induced predominantly through tougher regulation of the nutritional and portion size information provided.

The second paper in this theme takes a more direct, analytical approach examining how portion size might be regulated and what consequences this might have. Containing Big Soda: Countering Inducements to Buy Large-Size Sugary Drinks by Dobson, Chakraborty and Seaton addresses the major public concern expressed around the provision to consumers 
of large single-serves of energy-dense ("sugary") drinks. Even before we consider any public health concern, the authors develop an economic model highlighting that the provision and pricing of regular and large ("value") serves may capitalize on extracting market surplus from two quite distinct market segments, the health-conscious and the value-conscious.

Extending their analysis, the authors show that their model raises concerns about how public policy might seek to curb the consumption of super-sized sugary drinks. Specifically, they point out that a restriction on the sizes of sugary drinks might simply encourage vendors to adopt a work-around such as the provision of multiple-unit pricing which will preserve their profitability and undermine the public policy effort. An alternative approach might be to apply a soda-tax, but the authors point out that such a tax may need to be set fairly high to be effective.

The third paper in this theme presents a view quite different from the others in both this section and indeed, this special issue by examining the effect of restricted portion sizes (food intake) as managed by medical intervention. It is a contribution that demonstrates an $a$ priori awareness of the problematic aspects of the moralizing dimensions of this type of research (Askegaard et al. 2014). In Embodied transformations and food restrictions: The case of medicalized obesity by Ourahmoune, the relation between subject and object in terms of the process of size reduction is reversed. In portion size research, it is usually the variations and reduction in portion size of the (food) object that is studied. But what happens when the portion size is restricted, not in terms of the object but in terms of the subject? When, in other words, a reduction in food intake (i.e., portion size) is induced through medical intervention? Ourahmoune tries to provide an answer to this question through a Foucauldian analysis of discourses and practices on food quantities following bariatric surgery, thereby opening up a different set of reflections on structure-agency issues, so prevalent in food portion research. Through a discourse analysis based on participant 
observation studies, blog content and interviews with patients and doctors, four domains of post-surgery alterations of agency are suggested, each of them with positive as well as negative existential implications.

This piece of research tries to add complexity to the otherwise rather dichotomous public debate concerning weight loss surgery, as either an efficient tool in the fight against morbid obesity or a biopolitical repressive instrument creating docile bodies. Both these perspectives, it is argued, imply a passive view on the consumer, either as a recipient of service or as a victim of a dehumanized ideology of the body. Instead, it is proposed to consider weight loss surgery also as a source of agency with positive as well as negative outcomes. It is also concluded, that weight loss surgery has consequences not only for the food quantities consumed but also, for many consumers, may result in an alteration of taste structures.

\section{The Effect of Partitioning a Portion}

The second theme running through the papers in this special issue focuses on the partitioning of a portion. Partitioning is the division of a portion into sub-portions in an effort to change consumption. It is a tricky concept in that while researchers tend to focus on partitions as representing smaller portion sizes, the total amount of food served is typically held constant, and so number of partitions is necessarily confounded with size of partitions (Zlatevska, Dubelaar, Holden 2014). This may partly explain the existence of a rather paradoxical effect whereby partitioning can, under some circumstances, lead to increased consumption as summarised in a review by Holden \& Zlatevska (2015). In the current issue, there are three papers examining partitioning. The first examines partitioning as a method of controlling the portions of purchased food types. 
The paper Larger Partitions Lead to Larger Sales: Divided Grocery Carts Alter Purchase Norms and Increase Sales by Wansink, Soman and Herbst uses the novel approach of visually partitioning shopping carts, where a section of the cart is reserved for fruits and vegetables, to increase the size of portion of fresh produce purchased by the consumer. The effect occurs because, just like portion control (divided) plates, the partition suggests a norm for consumption. In a shopping setting, the partition encourages a consumer to be more motivated to balance the allocation of items between sections, ultimately encouraging them to purchase more fresh produce than they typically might have.

The strategy, tested in two studies (an online shopping scenario and in a field, supermarket setting), provides a win-win for both industry and consumers. The strength of the research is that it provides a simple strategy which can be implemented by both food retailers looking to increase sales of their perishable fresh goods, as well as consumers who can easily divide their own shopping carts with re-usable shopping boxes. The research highlights the benefits of using partitioning as a tool to nudge consumers into making healthier, more considered choices.

The second paper exploring the theme of partitioning explores the broader issue of food granularity, and the positive and negative ramifications of both partitioning food at both the level of both portions and food morsels. This manuscript demonstrates the need to separate partitions from morsels in order to understand the consequences and previous paradoxes exposed in partitioning studies. In the paper Honey they shrank the food! An integrative study of the impact of food granularity and its operationalization mode on consumption by Roose, Van Kerckhove, and Huyghe, the authors highlight that food granularity is confounded between number and size and delve into how these perceptual confounds change our appreciation of the food presented to us. Specifically, they point out 
how hedonic foods interact with our ability to engage restraint and note that this leads to the paradoxical outcome noted in previous literature.

These findings can be used to help those who are trying to exercise restraint and the companies aiming to assist such consumers by understanding how the paradox occurs and avoiding it in cases where the restrained eater will find themselves unable to stop eating. Potentially, this could lead to the ability to develop food packages that will more effectively address the needs of those attempting to control their food intake to control their weight.

The third paper in the partitioning theme Can Health 'Halos' Extend to Food Packaging? An Investigation into Food Healthfulness Perceptions and Serving Sizes on Consumption Decisions by Bui, Tangari and Haws explores the interaction of the perceived healthiness of food and partitioning (e.g., dividing a package into a multi-pack comprising multiple smaller portions) on consumption. Across three experimental studies, they found that intended and actual consumption of an unpartitioned package of food perceived to be healthier (granola) was higher than a partitioned version of the same food. Partitioning apparently had no effect on consumption of a food perceived to be unhealthier (cookies).

The authors argue that the implications are that we ought to be encouraging the partitioning of healthier foods so as to discourage excessive consumption of apparently healthful foods provided in unpartitioned packages. The authors note that this concern is particularly important for energy-dense foods (such as granola) which consumers perceive to be healthy. Providing unpartitioned packages of such apparently healthy foods may lead to excessive consumption.

\section{Portion size cognitions and perceptions}

The third theme is one of exploring how activating consumer cognitions and perceptions about food and portion sizes may have a helpful influence on reducing 
consumption. In this theme, a number of papers examine how changes in the way consumers imagine or conceptualise portion sizes can change how they respond to food.

The first paper explores this in the context of health messages. This is Your Stomach Speaking: Anthropomorphized Health Messages Reduce Portion Size Preferences Among the Powerless by Newton, Newton and Wong reports findings from two experiments which show that health messages endorsed by an anthropomorphized digestive system is an effective tool in reducing self-reported portion size preferences among the powerless. The effect occurs because anthropomorphized entities can be treated by humans as a potentially credible agent of social influence. Anthropomorphizing an internal body system that is susceptible to an adverse health outcome may elicit feelings of threat, in turn, motivating individuals to engage in health related behaviours.

The findings of the study are of particular import given that it is often difficult to design effective and impactful health communications. Humanizing elements of the body in health related messages is a novel method of shaping the behavioural preferences of consumers.

The second paper in this theme explores the concept of mindfulness and how it plays out in food consumption. Changing the influence of portion size on consumer behaviour via imagined consumption by Petit, Spence, Velasco, Woods and Cheok explores the idea of whether mindfulness has an impact on reducing the portion size effect. In particular, they present two studies showing that mental simulation of an eating experience offers some promise in reducing the portion size effect on intended consumption.

While the portion size effect is not eliminated, and the results still need to be extended to actual consumption, their results do provide encouraging support for the idea that mental simulation of eating a food portion, and perhaps mindfulness in general, can help reduce the portion size effect. 
The third paper in this theme addresses how we perceive volume and size when the objects being judged are placed in different formations. Spread or Stacked? Vertical versus Horizontal Food Presentation, Portion Size Perceptions, and Consumption by Szocs and Lefebvre adds to the growing body of literature exploring visual biases in size perception. In four studies, the authors show that food presentation has an influence on consumers' portion size perceptions, where consumers perceive portions of food to be smaller when they are presented vertically. Consumers use the surface area of the portion as a heuristic for estimations of overall portion size. The authors highlight that when looking down at a plate of food the surface area is more salient than the height of the food and surface area is positively correlated with overall portion size estimations. Food portions presented vertically have a smaller surface area than the same quantity of food spread out horizontally on plate. The authors note that these findings contribute to recent research which suggests that differences in portion size are easier to detect when reflected in a single dimension compared to multiple dimensions (Chandon and Ordabayeva, 2009) and that consumers are inaccurate at evaluating the size of a product (Chandon and Ordabayeva, 2009; Chandon and Wansink, 2007).

The research provides some interesting implications for both industry and consumers where horizontally spreading out food on plates might encourage consumers to eat less. While stacking food vertically might also nudge consumers into consuming more fruits and vegetables. A strength of the strategy is that it is easy, and cost effective to implement by food retailers.

The Special Section editors express their gratitude to Arch Woodside, Editor-in-Chief of Journal of Business Research, for the opportunity to develop this Special Section, and also thank the authors and reviewers who volunteered their time to help shape this special issue. Their tireless efforts have made it possible for us to present to you these papers. There were 27 papers submitted, of which these nine were accepted. Thirteen of the original submissions 
were rejected in the first round. The remaining fourteen were revise and resubmit, and five of those were rejected after the second review.

The editorial team thanks the following reviewers for their valuable help.

\begin{tabular}{|c|c|}
\hline Reviewer Name & Institution \\
\hline Goele Aerts & KU Leuven \\
\hline Lawrence Ang & Macquarie University \\
\hline Christina Anthony & University of Sydney \\
\hline David Arnott & Monash University \\
\hline Sharon Beatty & University of Alabama \\
\hline Michelle Bergadaa & Université de Genève \\
\hline Helene Brembeck & Gothenburg University \\
\hline Paul Burke & University of Technology Sydney \\
\hline Eugene Chan & University of Technology Sydney \\
\hline George Chryssochoidis & Kent University \\
\hline Rita Coelho do Vale & Universade Catolica Portuguesa \\
\hline Tara Diversi & Bond University \\
\hline Marcelo Gattermann Perin & $\begin{array}{l}\text { Pontifica Universidade Catolica do } \\
\text { Rio Grande do Sul }\end{array}$ \\
\hline Marina Girju & DePaul University \\
\hline Kissan Joseph & University of Kansas \\
\hline Inge Kersbergen & University of Liverpool \\
\hline Dorthe B. Kristensen & University of Southern Denmark \\
\hline Ming Lim & University of Leicester \\
\hline Natascha Loebnitz & Aarhus University \\
\hline
\end{tabular}




\begin{tabular}{|c|c|}
\hline Jay Majtyka & Bond University \\
\hline Dwight Merunka & IAE Aix-Marseille \\
\hline Elizabeth Minton & University of Wyoming \\
\hline Sonja Moetteli & ETH Zurich \\
\hline Risto Moisio & California State University Long Beach \\
\hline Elizabeth Moore & University of Notre Dame \\
\hline Jeff Murray & University of Arkansas \\
\hline Jacob Östberg & Stockholm University \\
\hline Mauricio Palmeira & Monash University \\
\hline Esther Papies & University of Glasgow \\
\hline Collin Payne & New Mexico State University \\
\hline Terri Rittenburg & University of Wyoming \\
\hline Eric Robinson & University of Liverpool \\
\hline John Schouten & Aalto University \\
\hline Carrie Skinner & Florida State University \\
\hline Ingrid Steenhuis & Vrije Universiteit Amsterdam \\
\hline Michal Strahelovitz & Victoria University of Wellington \\
\hline Chris Summers & University of South Carolina \\
\hline Courtney Szocs & Portland State University \\
\hline Ali Tamadoni & Deakin University \\
\hline Marcus Tan & Bond University \\
\hline Dominic Thomas & Monash University \\
\hline Thyra Uth Thomsen & Copenhagen Business School \\
\hline Murat Usta & Dalhousie University \\
\hline
\end{tabular}




\begin{tabular}{|c|c|}
\hline Anneleen Van Kerckhove & Gent University \\
\hline Ellen Van Kleef & Wageningen University \\
\hline Lenny Vartanian & University of New South Wales \\
\hline Sonia Vilches-Montero & University of Newcastle \\
\hline Andrea Vocino & Deakin University \\
\hline Luk Warlop & KU Leuven \\
\hline Fred Yamoah & University of Hertfordshire \\
\hline
\end{tabular}




\section{References}

Askegaard, S., Ordabayeva, N., Chandon, P., Cheung, T., Chytkova, Z., Cornil, Y., Corus, C., Edell, J.A., Junghans A.F., Kristensen, D.B., Mathras, D., Mikkonen, I., Miller, E.G., Sayarh, N. \& Werle, C, (2014), "Moralities of Food and Health Research”, Journal of Marketing Management, 30 (17/18), 1800-1832.

Chandon, P. and Ordabayeva, N. (2009). Supersize in one dimension, downsize in three dimensions: effects of spatial dimensionality on size perceptions and preferences. Journal of Marketing Research, 46(6), 739-753

Chandon, P. and Wansink, B. (2007). Is obesity caused by calorie underestimation? A psychophysical model of meal size estimation. Journal of Marketing Research, 44 (February), 84-99.

Dobbs, Richard, Corinne Sawers, Fraser Thompson, James Manyika; Jonathan Woetzel; Peter Child; Sorcha McKenna; Angela Spatharou (2014) Overcoming obesity: An Initial economic analysis. McKinsey Global Institute.

Flatt, J. P. (1997). How NOT to approach the obesity problem. Obesity research, 5 (6), 632633.

Holden, S. S., \& Zlatevska, N., (2015). The partitioning paradox: the big bite around small packages. International Journal of Research in Marketing, 32(2), 230-233.

Pi-Sunyer, X. (2003). A clinical view of the obesity problem. Science, 299 (5608), 859-860. Rolls, Kling, \& Roe (2016)

Rittel, Horst W. J.; Melvin M. Webber (1973). "Dilemmas in a General Theory of Planning" Policy Sciences. 4: 155-169

Seiders,Kathleen, Ross D. Petty (2004) Obesity and the Role of Food Marketing: A Policy Analysis of Issues and Remedies. Journal of Public Policy \& Marketing: Fall 2004, Vol. 23, No. 2, pp. 153-169. 
World Health Organization (2012), World Health Statistics 2012.

World Health Organization (2016), http://www.who.int/mediacentre/factsheets/fs311/en/, accessed 22 August 2016.

Zlatevska, N., Dubelaar, C., \& Holden, S. S. (2014). Sizing up the effect of portion size on consumption: a meta-analytic review. Journal of Marketing,78(3), 140-154.

Zlatevska, N. \& Holden, S.S. (2016) Nudging the weight off: small portions, big effects. Theory \& Practice in Marketing Conference, Houston, TX. 